\title{
Educational Research, Social Change and the Challenge to Methodology: A Study in the Sociology of Knowledge
}

\author{
H. Svi Shapiro \\ University of North Carolina, Greensboro

\section{Introduction: The Social Crisis and the Emerging Challenge to Positivism}

A quiet revolution is occuring in the realm of educational research. On an unprecedented scale researchers and students of education have begun to propose and develop alternative methods of inquiry to the dominant "scientific" or positivist models. A plethora of non-quantitative, "qualitative" studies have begun to appear. In addition, a profusion of theoretical critiques and methodological discussions forms an increasingly prominent part of the research literature. More and more graduate training in research methods includes some recognition of a "humanistic" or non-positivist tradition in educational scholarship.

Such work goes by a multitude of titles: phenomenological research, interpretive, case-study, ethnographic, etc. It claims descent from a variety of methodological and theoretical progenitors: phenomenology, hermeneutics, symbolic interactionism, ethnomethodology, anthropological ethnography, the verstehen tradition in social research, and critical sociology, among them. Whatever their differences-and they are certainly substantial - the new forms of inquiry or research do, I believe, have a number of commonalities. Among these is a rejection of quantification as a necessary ingredient of research, a more critical attitude towards the certainties or the adequacy of empirical evidence, recognition of the pervasiveness of subjectivity or consciousness in the accumulation of data, and attention to the existential moment and concreteness of experience (rather than the abstracted evidence of nomothetically-oriented inquiry).

These challenges to the dominant research paradigm in education do no more than follow challenges which have been emerging in the entire field of the social sciences and which are part of a long tradition critical of the positivist approach to the understanding of human experience. ${ }^{1}$ Yet surprisingly, few in the field of educational research have concerned themselves with the reasons for the changes. This is, perhaps, an example of our culture's tendency toward historical amnesia-the inability to see the present as history. An analysis of the present methodological challenge in educational research which ignores developments in the larger realm of social research would be parochial indeed, and would miss, I believe, the fundamental historical, cultural and sociological conditions responsible for the present situation.

Nor can challenges to the dominant paradigm in research be seen as resulting simply from the persuasiveness of recent critical scholars. For what must be explained, after the incisiveness of this scholarship is recognized, is what in the wider situation might be responsible for the interest and receptiveness to it among so many students. This, I believe, can be answered only through a consideration of the relationship of such work to the social conditions in which it is being received and utilizedconditions which, I will argue, have precipitated a crisis in the way we view or understand our world. 


\section{Disordered Reality and the Declining Faith in Nomothetic Research}

Perhaps most at odds with the designs of normal science-and social science-is the avoidance in the new research of any necessary claims to generalizability. In its place such research frequently emphasizes the particularistic and the existential. Not so much rejecting the value of generalizable results, such goals assume a secondary or incidental character. What is of most interest is the attempt to account for and to describe particular, even idiosyncratic, aspects of human behavior. While others may find that such accounts resonate with their own inquiries, this is viewed as a fortunate, though not necessary, consequence of the work. ${ }^{2}$

In this sense the new research minimizes what is certainly the most seductive aspect of normal science-the ability to apprehend an entire universe of study through investigations of a limited sample. Indeed, it is precisely here, through the perfection of techniques of sampling that scientific forms of inquiry provide such a powerful instrument for generating knowledge. ${ }^{3}$ Such developments are inextricably tied up with the desire to make predictable human behavior: to view such behavior (and the experiences underpinning it) as determined by the laws of causality. It is to argue that under specific and constant conditions and in the presence of a particular stimulus, a universal response may be attained.

It is precisely in this preoccupation with notions of generalizability, causality, and prediction that Jurgen Habermas (1971) and other critics of positivism have argued that the procedures and goals of normal science are inseparable from concerns with political control and social domination. In his discussion of the relationship between the desire for more political control and the social scientific pursuit of generalizable information, Alvin Gouldner (1970) notes the confluence of the hugely expanded interventionist state in American society with the claims for the enhanced predictability of human responses brought about through the methodological triumphs of modern social science. It is these successes (or at least, the claims thereof) that made the "social policy" state of our time, with its unceasing legislation of our social, economic, and educational lives. Certainly the myriad interventions of the state in education-in institutional reform, curriculum change, etc.--are predicated on a belief in the capacity of research to make valid generalizations about an entire population and accurate predictions concerning interventions and their effect. With the help of social science, critical commentators maintain, and political rulers aspire, to implement policies-and ensure human responses-conducive to the stable reproduction of the political or social structure. Liberal reforms are thus seen as facilitating adjustments that make possible the avoidance of radical re-arrangements in the social system. ${ }^{4}$

At its core social policy and social reform presupposes an ideology-or a faith-in which social actors obey rational (i.e. predictable) criteria for their decision-making and their behavior. It is possible, I believe, to suggest that it is precisely such an ideology (or faith) that has become eroded in the past decade. In the U.S. (and in Western Europe) notions of lawful causality and predictable formulations of social behavior confront societal realities with increasing dissonance. There is a widely described 
perception of a world "out of control." At every level-economic, political, social, cultural-there appears to be a deepening sense in which society appears unresponsive to organized interventions. In the economic domain liberal Keynesianism is followed by conservative supply-side nostrums in what appears as an increasingly fruitless attempt to maintain a stable economy of low inflation, full or near-full employment, and budgetary solvency. American institutions of government have been headed by presidents who, on the last two occasions, arrived in their positions through campaigns that emphasized the uncontrollable character of the present political-administrative apparatus. Interventions of the state that were advertized as intended to eliminate poverty have failed, the perennial "war on crime" seems to produce few victories, and educational institutions seem not to produce the promised results. Indeed there is a frequent perception that social, economic, or educational policies promising a rational and ordered world do no such thing; it is the uncontrollable, the unpredictable, and the chaotic that seem to characterize the world of late capitalism. ${ }^{5}$ Perhaps the heaviest blow in this respect have been the failures of science - the very symbol of lawful rationality-to successfully predict the deleterious effects of technology on the human environment. ${ }^{6}$

It is within the context of eroding rationality and lawfulness that one may locate some of the movement away from social and educational inquiry based on the premises of normal science. Its result, as we noted, is research that has turned away from the preoccupation with universal predictions or generalizable examples of causality, emphasizing instead investigations of individual situations, case studies, and ideographic phenomena. Increasingly, research is seen as a process that emphasizes sensitivity to the situation at hand rather than the capacity to make deductive inferences about what, in a rationally ordered universe, one might expect in any other apparently similar situation. The reduced scope of such investigation may be seen then as, at least in part, a response to the Zeitgeist of our time, to the sense of disordered reality and declining faith in the ability of social research to make good on the promises of scientific techniques and a positivist methodology.

\section{The Growth of Phenomenological Research and the Uncertainties of Social Reality}

The tumultuous events and changes of recent times have been responsible in other ways for the emergence of the new forms of inquiry. More than anything these changes have led to an erosion of the "facticity" with which our world is apprehended. Characteristic of periods of rapid change, social realities in this time have appeared far less massive or impenetrable than in previous times. ${ }^{7}$ In many areas of our world a sense of fragility or contingency has become connected to the previously taken-forgranted features of the world; its massive externality appears vulnerable or even in a state of disintegration. Roles, institutions, and norms appear less and less often to carry the determining power of transcendent beliefs; fewer areas of the social world pass any longer as natural or inevitable. ${ }^{8}$ 
Instead, we are urged to perceive rules, behavior, or experience as the product of individual choice and freely arrived at preferences. ${ }^{9}$ In the consumption-oriented capitalism of our time the dominant ideology insists that the immediate gratification of individual needs, not the compliance with traditional norms, be the criteria for our decisionmaking. ${ }^{10}$ To whatever extent the ideological mirror may distort (indeed, in the recession of 1982-3, grotesquely so) the experiences of many, we are nonetheless urged to consider ourselves the only transcendent categories in a world which is of only temporary or pragmatic value. The erosion of the firmness of roles and the disintegration of the solidity of institutions have "de-objectified" the world. School, marriage, parenthood, sexual identity, work and achievement, racial divisions, and political parties have lost their taken-for-grantedness. Each is seen as increasingly socially constructed, the product of specific forms of historical development, and sustained by particular configurations of political power, social interests, or tradition. ${ }^{11}$

We have alluded to the influence of a consumption-oriented capitalism in the loss of the fixity of our world. In the 1960s, however, there emerged other powerful contributors to the dissolution of this naturally-appearing world: the waves of assaults launched against the givenness of social roles -by Blacks, women, students, homosexuals, senior citizens, the handicapped, and others; the insistent scrutiny and undeterred exposure in the media and elsewhere, of government, the military, sexuality, and just about any other previously immune or sacrosanct area of concern; and the effects of art, theatre, movies, music, and forms of popular culture that created what Daniel Bell (1976) calls the "psychedelic bazaar" and celebrated the multiplicity of realities that are available to the unrepressed consciousness. While the 1960 slogan of French students in revolt-"All power to the imagination"-may have not overturned society, it has unleashed, according to Hans Peter Dreitzel (1977), a sensibility which continues to promote and undermine the established practices of the bureaucratic instrumentally-oriented world. The 1960s saw the launching of a powerful movement which has continued to dissolve the rigid externality of social reality, leaving in its place a sense in which human actions and consciousness may make or re-make the world.

It is precisely this pervasive disintegration of the social reality that constitutes our everyday world which has been a key underlying concern in the new research. There has, for example, been an extraordinary interest in the work of Alfred Schutz (1973). Schutz's work has been a frequent starting point for the now bourgeoning literature on the socially constructed nature of everyday reality, and his work on this reality makes a crucial contribution to the understanding of its now apparently precarious nature. Schutz notes that the reality of everyday life consists of a number of presuppositions or assumptions which include the notion of a tacit taken-for-granted world, an assumed practical interest in that world, and an assumption that it is intersubjectively created and sustained. His notion of multiple realities also resonates powerfully with the recent turn towards Eastern and mystical notions with their assertions of the primacy of consciousness over the paramountcy of the everyday world (Mehan and Wood, 1975, p. 31). Schutz's work has provided the underpinnings of a 
phenomenological revival in research that has focused more and more on the exploration of the taken-for-granted aspects of the everyday world and the intersubjective constituting of reality. Nowhere has this concern been more clearly evidenced than in educational studies. Studies in the constituting of the school world and pedagogic categories-the social construction of intelligence, ability, achievement, "good" and "bad" behavior-have become legion; ${ }^{12}$ descriptions of "being" a teacher, administrator, student, and the categories of childhood and adolescence have reached high degrees of sophistication. ${ }^{13} \mathrm{In}$ all of this work there is an effort to utilize Husserl's notion (1982) of "bracketing" the everyday world (suspending our preconceptions about it) so that one may explore the tacit understandings from which the social and educational world is constructed.

While the phenomenological orientation of the new research is, I believe, in part at least, an expression of the disintegrating social fabric, it is not the only expression. The bourgeoning field of radical or critical analysis in education has asserted the need to merge a view of reality that is intersubjective and socially constructed with one that emphasizes the centrality of the processes of domination and control in contemporary society. Such a perspective claims the need to see the phenomenologically described reality within a context where those who have disproportionate access to material and ideological resources are able to play the dominant role in defining how this reality appears. ${ }^{14}$ While rejecting the empirical certainties of a positivist Marxism, such critical scholarship has sought to unite a phenomenological notion of a humanly constructed world with a Marxian emphasis on issues of power, social interest, and control. There is, in this work, an emphasis on the need to move beyond the reified and positivist view of social "facts" and "realities" and to see human praxis (the dialectic of practical activity and awareness) as central. The proliferating scholarship written within this vein makes even clearer the connection between current modes of inquiry and the experience of a social world increasingly uncertain and open to question.

\section{The Disintegration of Culture and the Emerging Importance of "Reflexivity"}

The dissolution of a clear and unambiguous notion of social reality in the present era has turned social research not only towards a concern with the constituting of the social world, but also towards a focus on culture and what has been called the telic principle. In contrast to the concern with causality (which attempts to explicate the regularities in social life), the telic principle refers to the purpose, means, and ends according to which men and women conduct their lives. It is the total configuration of human purposes and ends at any particular time and place that constitutes the realm of culture. Reflecting a concern with the nature of the lived culture, the new research has emphasized the question of meanings in human behavior and sought ways to make valid interpretation of human intentions.

The crisis of social reality I have described above is, at the same time, a crisis of culture. While the former has stimulated the search for the means 
by which reality is socially constructed, the latter has engendered a search for the means by which human consciousness may be known. The crisis of culture underpinning the interpretive bent of the new research has been well described by a number of social commentators. Jurgen Habermas, for example, has described how the rationalizing ethos of advanced capitalist societies has increasingly encroached upon and undermined the traditional and taken-for-granted aspects of culture (1975). This ethos has forced attitudes, beliefs, values, and practices to confront the process of administrative and political discourse--and the need to justify themselves before a tribunal of democratic or quasi-democratic inspectors. He writes:

At every level, administrative planning produces unintended unsettling and publicizing effects. These effects weaken the justification potential of traditions that have been flushed out of their nature-like course of development. Once their unquestionable character has been destroyed, the stabilization of validity claims can succeed only through discourse. The stirring up of cultural affairs that are taken for granted thus furthers the politicization of areas of life previously assigned to the private sphere. (1975, p. 172)

Habermas also notes the growing conflict between cultural meanings and values in such societies. He describes the erosion of "achievement ideology" (a key element of traditional bourgeois culture) as it is confronted by the counter-cultural values of what he calls "post-auratic art," a universalist morality, and (perhaps most devastatingly) the inability of a declining economic system to deliver on the promise of more goods and services (1975).

The dissolution of traditional bourgeois culture is described, too, by Daniel Bell (1976). For Bell, the values of achievement ideology are a part of the larger configuration of traditional bourgeois morality which includes industriousness, thrift, frugality, self-control, and impulse renunciation. Against these traditional virtues (which Bell described as centering on the Protestant concern with work and the Puritan emphasis on a "forbidding attitude towards life") the new or consumption-oriented capitalism encourages a culture that is primarily hedonistic and is concerned with fun, play, display, and pleasure. The oppositional nature of those values, Bell notes, leaves a fundamental contradiction in the norms of the culture:

On the one hand, the business corporation wants an individual to work hard, pursue a career, accept delayed gratification - to be, in the crude sense, an organization man. And yet, in its products and its advertisements, the corporation promotes pleasure, instant joy, relaxation and letting go. One is to be "straight" by day and a "swinger" by night. (1976, pp. 71-72)

Bell notes that in place of the traditional virtues of industry, thrift, discipline, and sobriety, the contemporary world of hedonism is one of fashion, photography, advertizing, television, and travel. He asserts that while, with traditional culture, gratification of forbidden impulses aroused guilt, now failure to have fun and successfully pursue pleasure lowers one's self-esteem.

Studies by a host of recent cultural observers have amplified the breakup of traditional norms. Theodore Roszack, Hans Dreitzel, and Daniel Yankelovitch have each argued that an alternative, more 
expressive, individually-liberating set of cultural norms has begun to challenge and undermine traditional expectations. Daniel Yankelovitch concludes that the "new consciousness" which developed in the 1960s on the campuses and in the counter-culture has now worked its way through large sections of the middle class and parts of the working class:

By the seventies ... most Americans-were involved in projects to prove that life can be more than a grim economic chore. Americans from every walk of life were suddenly eager to give more meaning to their lives, to find fuller selfexpression... The search for self-fulfillment has developed into a prime source of energy in American culture ... The life experiments of self-fulfillment seekers often collide violently with traditional rules, creating a national battle of moral norms. (1981, p. 5)

Whatever their disagreements, all of these studies underline the extent to which cultural change and the conflict and dissolution of values mark the contemporary scene. To whatever extent these results are viewed as positive or negative, liberating or dehumanizing, such changes in our culture are certain to generate profound anxieties about the questions of meaning, purpose, and ends in human life. And it is precisely such anxiety that, I believe, provides a powerful impetus in the emergence of the new research. In particular, such research has as a central concern the issue of human intentions, purposes, and motives. The study of human behavior is focused on the "in order to" (rather than the "because of") dimension of understanding. Indeed, it is this concern that has led to the frequent characterization of such research as "interpretive." It is a research which concerns itself with the ways in which people understand, make sense of, and hence, act in the world.

The focus on human consciousness that has emerged from the crisis in our culture has meant a growing dissatisfaction with research that is organized around the discovery of regularities or nomothetic qualities in human behavior. There is felt to be a need to go beyond what now appears as the fundamentally descriptive nature of traditional research to a deeper level of explanation. This latter approach has embraced hermeneutics, the methodological tradition of Verstehen, as well as Marxian and Freudian theories of the unconscious. While there has been, and continues to be, enormous philosophical discussion and disagreement concerning such inquiry, there are certainly areas of general agreement. There is, for example, a customary emphasis on the way individuals or collectivities perceive the world; there is a concern with how, and what aspects of, the "blooming buzzing, confusion" of human experience come to be distinguished as meaningful and coherent; there is a frequent recognition of the distinction between a world of "understanding" and one of "interpretation." The latter refers to the separation between a world that is pre-conscious and taken-for-granted, and one that requires an active process of meaning-making..$^{15}$ Of course, closely related to the growing concern with questions of meaning and interpretation has been an expanding interest in the sociology of knowledge as well as in issues of language.

It must be emphasized that whatever the shared concerns of the new research there remain very significant differences. Thus, for example, the 
notion of interpretive accounts resting on intuitive, empathetic leaps into the consciousness of others is rejected by those who argue the need to construct such accounts by reliance on structuralist methods of analysis. Despite these differences it is, nevertheless, possible to view the bourgeoning growth of all such work as, in part at least, a response to the cultural anxieties and ambiguities of our age. At a time when meanings, motives, and purposes become more unfixed, uncertain, and of questionable value, interpretive research, with its emphasis on reflexivity, urges us to make our own consciousness the primary object of inquiry. ${ }^{16}$

\section{The Dramaturgical Perspective and the Agony of the Interpersonal World}

Perhaps the most immediately painful effects of the present conflictridden and tension-fraught social situation are in the realm of interpersonal relations. Out of the anxieties, stresses, and strains of this realm we may find the roots of a strong concern, in the new inquiry, for the means by which social relations are constructed, maintained, or destroyed. Alvin Gouldner (1970, pp.378-390) has brilliantly summarized this connection in his discussion of the work of Erving Goffman.

Gouldner asserts that Goffman's image of social life "is not of firm, well-bounded social structures, but rather of a loosely stranded, crisscrossing, swaying catwalk along which men dart precariously" (1970, p. 379). He suggests that in this view people are acrobatic actors and gamesmen who have, somehow, become disengaged from social structures and are growing detached even from culturally standardized roles. They are seen, he says, less as products of the system than as individuals "working the system" for the enhancement of self. There is communicated in this, he notes, a sense of the precariousness of the world. In such a world human conduct is seen as essentially concerned with fostering and maintaining a specific conception of the self before others. The outcome of this effort, he states, is not seen as depending on what men "really" do in the world, or on their works, but on their ability to skillfully mobilize convincing props, settings, fronts, or manners: "A man's value in the world, then, depends upon his appearances, and not, as it had to the classical bourgeois, on his talents, abilities or achievements" (1970, p. 380).

Gouldner locates this new concern with "performance" and "roles" in a world in which a stratum of the middle class no longer believes that hard work is useful, or that success depends on diligent application: "In this new world there is a keen sense of the irrationality of the relationship between individuals' achievement and the magnitude of reward, between actual contribution and social reputation. It is the world of the high-priced Hollywood star and of the market for stocks, whose prices bear little relation to their earnings" (1970, p. 381).

Dramaturgy ${ }^{17}$ as Gouldner calls it, marks the transition from an older economy centered on production to a new one centered on mass-marketing and promotion, including the marketing of the self. It is symptomatic of the new "tertiary economy" in which men increasingly produce "performances" rather than things. And in a society in which, as Gouldner 
asserts, men have no real choices in either the economic or the political marketplace, appearances come to count most heavily; style sustains the illusion of choice. Style, he says, becomes the strategy of interpersonal legitimation for those who are disengaged from work and for whom morality itself has become a prudent conscience.

Gouldner has argued that such a "social theory" appeals to men who live in or must deal with large-scale bureaucracies that have a juggernaut momentum of their own and are little amenable to the influence of individuals. In such institutions individuals become readily interchangeable and their sense of worth and potency become impaired:

Having little.impact on the organization as a whole, they focus on the management of impressions, seeking to be noticed and differentiated from others, and attempting thereby to establish their individual worth and potency". (1970, p. 382)

The new bourgeois world of "impression-management," says Gouldner, is inhabited by anxious other-directed men with sweating palms who live in constant fear of exposure by others and of inadvertent self-betrayal. Social relationships become an interaction of espionage agents, each seeking to convince the other that he really is what he claims to be, and each seeking to penetrate the other's "cover."

The same emphasis on appearance, convincing others of one's value, and pretense is at the core of Christopher Lasch's contemporary narcissistic personality:

In a society in which the dream of success has been drained of any meaning beyond itself, men have nothing against which to measure their achievement except the achievements of others... The good opinion of friends and neighbors which formerly informed a man that he had lived a useful life rested on appreciation of his accomplishments. Today men seek the kind of approval that applauds not their accomplishments but their personal attributes. ... They want to be envied rather than respected ... what a man does matters less than the fact that he has "made it." (1979, pp. 116-117)

More and more, notes Lasch, "credibility" and the impression one makes on others matter more than successful completion of the task at hand. Projecting the right image (not matters of achievement) becomes the consuming passion of politicians, business executives, or, indeed, anyone else on the move or on the make. Lasch argues that the present mania for the proper technique and the concern for the good performance (in everything from one's profession to sex) hides a deeper determination to manipulate the feelings of others to our advantage:

The search for competitive advantage through emotional manipulation increasingly shapes not only personal relations but relations at work as well; it is for this reason that sociability can now function as an extension of work by other means. Personal life, no longer a refuge from deprivation suffered at work, has become as anarchical, as warlike and as full of stress as the marketplace itself. (1970, p. 126)

Lasch suggests that the recent vogue of "assertiveness therapy" is a counter-program designed to equip the patient with defenses against manipulation. It appeals, he says, to the growing recognition that agility in interpersonal relations determines what looks on the surface like 
achievement. Assertiveness training seeks to rid the patient of feelings of anxiety, ignorance, and guilt which are used efficiently by other people to get us to do what they want. The importance, says Lasch, of such programs lies not so much in their objectives as in the anxiety to which they appeal and the vision of reality that informs them:

The perception that success depends on psychological manipulation and that all of life, even the ostensibly achievement-oriented realm of work, centers on the struggle for interpersonal advantage, the deadly game of intimidating friends and seducing people. (1970, pp. 126-127)

It is within this context of embattled personal relations that one finds, I believe, the roots of a significant component of the new research. The intensifying tenuousness of such relations, whether in the world of public or private intercourse, compels our concern with the means by which individuals are able to construct and sustain these relations. In such a world, infused as it is with the notions of appropriate appearances, manipulation of impressions and managed images, participants are viewed as the active theorists or methodologists of their interpersonal reality. Such a reality, it is argued, stands in permanent danger of collapse if roles are not adequately assumed, identities do not achieve appropriate recognition, or communications skills are not effectively deployed. It is a perspective that has especially incorporated the work of role theorists, labelling theorists, the social psychology of G. H. Mead, as well as communications theory, and has found expression in the study of areas as diverse as criminology and family therapy. ${ }^{18}$ In the field of education a plethora of recent studies is evidence of an increasing utilization of such a view. Perhaps most influential among them has been work that has focused on the assignment of educational "labels," categories, and identities to students through the interpersonal activities of teachers, students, parents, and administrators. ${ }^{19}$ Such work contributes, I believe, to the development of Gouldner's notion of the "dramaturgical" perspective on human relationships, a perspective whose emphasis on the construction of appearances and the communication of images is now powerfully impelled by the present sociology of our interpersonal world.

\section{Conclusions: Revolt Against Science - Towards a New Consciousness?}

There is one other phenomenon that must be considered in attempting to locate the sociological ground on which the new research has arisen. In a society embracing technological goals, values, criteria, and meaning to an unparalleled degree, there has developed in the last ten years or so the paradox of a counterveiling culture-one that feels increasing apprehension at scientistic values and procedures. It is clear that while this counter-culture developed in the 1960s, it has continued to permeate the sensibilities and consciousness of the 70s and 80s. Hans Peter Dreitzel argues that at the core of this development has been a reinterpretation of the classic bourgeois attitude towards nature:

Prepared in the long history of the demystification of nature in the JudaicChristian tradition, the development of the scientific world view provided the bourgeoisie with the instrumental attitude towards nature which became the basis for its economic achievements. Nature, stripped from all magical projections, became a mere resource for exploitation ... (1977, p. 100) 


\section{He continues:}

It is my thesis that with the decreasing growth rates in all industrial societies and with increasing psychological pauperization the future function of culture will be mainly a reinterpretation of our relationship to nature. The beginning of this development can be seen today in the growing ecological consciousness, the increasing public debate on issues of physical and mental health, and the rise of syncretistic religious movements which emphasize a cosmological equilibrium between nature and consciousness. (1977, p. 100)

It is not the place here to elaborate all of the causes for these developments. Certainly one can identify the increasing awareness of the hazards that accompany uncontrolled technological change, most notably in the depletion of resources, environmental pollution, and the dangers of nuclear power. There are also the increasingly apparent economic (and of course, human) effects-unemployment through automation, rapid obsolescence, the need for massive and continual infusions of capital to fund research. And there is, perhaps, the psychic cost of a world increasingly inaccessible to anyone but "experts," and in which there appears to be a powerful urge to replace human capabilities with mechanical functions. The designation of a computer as Time Magazine's 1982 "Man of the Year" is perhaps emblematic of this trend.

Whatever the causes, it is clear that they have precipitated a movement which questions the sole propriety of instrumental rationality, the anthopocentric universe, the efficacy of reason in controlling man's future, a view of time and change as essentially progressive, and the privileged position assigned to intellectuals and experts..$^{20}$ In education, for example (perhaps especially), the feeling grows that experts may know not much more than common practitioners or laymen: that the complex languages of researchers bring us little closer to apprehending the realities of classroom or school. Indeed, the abstractions and reifications of their languages actually seem to distance us from the worlds inhabited by practitioners or students. There is a sense now, perhaps, that the fragmented concerns of traditional researchers, accompanied by their efforts to remove all traces of subjectivity from their inquiries, leave descriptions peculiarly out of touch with the existential realities of people's lives. The scientific method appears to move us away from the educational world rather than towards it.

It is certainly true that whatever trends or counter-trends are discernible around the issue of science and scientific procedures in our society, they are of a complex nature. Hesitation, ambivalence, or even outright resistence, for example, must not be mistaken for a full-blown revolt against science. There is, more probably, a widening cognizance of the growing tension between the human benefits that are the results of technology and scientific forms of understanding, and the dehumanizing and imperilling consequences of scientific "progress." Certainly there is increasing evidence of a growing skepticism toward the monolithic use of scientific criteria, values, and epistemology as the sole means by which one may develop understanding or make judgements. There is, for the first time, a widening belief that neither the testimony of experts nor their particular views of the truth represent all that can or needs to be said on 
matters of human and social consequence. The scientific method, it is argued, provides particular forms of knowledge or understanding which are in no way exhaustive of our activity. Positivistically oriented research in education, or elsewhere, with its demand for objectivity, causal-models, quantification, and empirical evidence, provides only one lens among several with which to view human experience or reality. It is, however, a lens that until recently has admitted to few of its own distortions or mystifications. The movement towards new methodologies in educational inquiry must be seen as part of a wider movement critical of the epistemological and political dominance of positivism in our culture-a dominance that for growing numbers represents an inadequate framework within which to understand our own existence and on which to make socially significant judgements.

Whether in education or in other areas of human inquiry, there is a growing sense that the language of science speaks only partially, and sometimes not at all, to the concerns, the sensibilities, and lives of human beings. Indeed, for some, it is a language that is viewed as, in part at least, constitutive of the very problems of our civilization rather than the means by which such problems might be solved. In this sense the struggle to create a new paradigm (or paradigms) for educational inquiry must be seen as part of a larger human struggle: one that is centered here on issues of methodological freedom and epistemological diversity, but that embraces in the sweep of its discourse the claims of a much wider and more farreaching liberation of consciousness. The sociological roots of the new forms of inquiry make clear that what is involved is not merely a matter of abstract, theoretical dispute-but one that inextricably involves issues of political control, cultural hegemony, and the defining of social reality. In this sense what is at stake in the escalating conflict over the nature of social and educational research represents far more than a question of primacy over some remote corner of academic territory. It also inevitably implies the struggle for primacy over issues pertaining to the relationship between existence, consciousness, and human values-issues that are inseparable from the profoundest social, ethical, and political considerations in the lives of people.

\section{Notes}

1. Of course such a literature is now immense. Significant authors include

R. V. Feyeraband, L. Goldman, J. Habermas, M. Horkheimer, L. Kolakowski, T. Kuhn, J. Lakatos, H. Marcuse, P. Winch. For a good summary of some of the arguments see R. Bernstein, The Restructuring of Social and Political Theory (N.Y.: Harcourt, Brace, 1976).

2. For a good discussion of the differences in research methodologies around the issue of generalizability see Severyn T. Bruyn, The Human Perspective in Sociology (N.J.: Prentice-Hall, 1966).

3. For an interesting, somewhat offbeat, discussion of sampling in social inquiry see J. Ford, Paradigms and Fairy Tales, Vol. 1 (London: Routledge and Kegan Paul, 1975).

4. See, for example, Frances Fox Piven and Richard A. Cloward, Regulating the Poor (N.Y.: Pantheon, 1971).

5. See, for example, C. Lasch, The Culture of Narcissism (N.Y.: Warner, 1979). 
6. For a recent summary of some of the arguments concerning technological determinism see M. Carnoy and D. Shearer, Economic Democracy (N.Y.: M. E. Sharpe, 1980), Ch. 5.

7. The outstanding work dealing with the phenomenon of the reification of social reality is P. Berger and T. Luckmann's, The Social Construction of Reality (N.Y.: Doubleday, 1966). See also A. Giddens, Central Problems in Social Theory (Berkeley: University of California Press, 1979).

8. For a recent investigation of this phenomenon in American life see D. Yankelovitch, New Rules (N.Y.: Random House, 1981).

9. See, for example, P. Slater, The Pursuit of Loneliness (Boston: Beacon, 1976). Also, T. Roszack, Person/Planet (N.Y.: Anchor, 1978).

10. See, for example, D. Bell, The Cultural Contradictions of Capitalism (N.Y.: Basic, 1976).

11. J. Habermas, Legitimation Crisis (Boston: Beacon, 1975).

12. Typical of such work is John Beck, Chris Jenks, Nell Keddie and Michael F. D. Young (eds.) Towards a Sociology of Education (N.J.: Transaction Books, 1976).

13. See, for example, David E. Denton, Existentialism and Phenomenology in Education: Collected Essays (N.Y.: Teachers College Press, 1974).

14. See, for example, H. Giroux, Ideology, Culture and the Process of Schooling (Philadelphia: Temple University, 1981).

15. For a fuller description of this see Mehan and Wood, The Reality of Ethnomethodology (Chapter on the 'Hermeneutic Spiral').

16. See, for example, Z. Bauman, Hermeneutics and Social Science (N.Y.: Columbia University, 1978).

17. While Gouldner uses this term to refer to the work of Erving Goffman it makes sense, I believe, to expand the meaning embodied by it to include other related (though certainly not synonymous) avenues of inquiry. We might include here modes of inquiry that, in some way, make use of role theory, labelling theory, some aspects of ethnomethodology and phenomenological sociology.

18. On family therapy see, for example, M. Poster, Critical Theory of the Family (N.Y.: Seabury, 1978).

19. See, for example, the work of Ray Rist. 'Becoming a Success or Failure in School: A Theoretical and Methodological Synthesis,' in A. H. Halsey and J. Karabel (eds.), Power and Ideology in Education (N.Y.: Oxford, 1976). See also R. Sharp and A. Green, Education and Social Control (London: Routledge and Kegan Paul, 1975).

20. See C. A. Powers, 'The Reproduction of Technological Consciousness: Locating The Ideological Foundations of a Radical Pedagogy' in Teachers College Record, Vol. 83, No. 4 (Summer, 1982).

\section{References}

Bell, D. (1976). The Cultural Contradictions of Capitalism. New York: Basic.

Dreitzel, H. P. (1977). On the political meaning of culture. In N. Birnbaum, Beyond the Crisis. London: Oxford University.

Gouldner, A. (1970). The Coming Crisis of Western Sociology. New York: Basic.

Habermas, J. (1971). Knowledge and Human Interests. Boston: Beacon.

Habermas, J. (1975). Legitimation Crisis. Boston: Beacon.

Husserl, E. (1982). Logical Investigations. (Vol. 1 and 2). London: Routledge and Kegan Paul.

Lasch, C. (1979). The Culture of Narcissism. New York: Warner.

Mehan, H., \& Wood, H. (1975). The Reality of Ethnomethodology. New York: Wiley.

Schutz, A. (1973). Collected Papers. (Vol. 1, 2 and 3). The Hague: Martinus Nijhoff.

Yankelovitch, D. (1981). New Rules. New York: Random House. 